\title{
openheart Impact of prior oral anticoagulant use and outcomes on patients from secondary analysis in the AUGUSTUS trial
}

\author{
Robert C. Welsh (D) , ${ }^{1}$ Payam Dehghani, ${ }^{2}$ Renato Lopes, ${ }^{3}$ Daniel M Wojdyla, ${ }^{3}$ \\ Ronald Aronson, ${ }^{4}$ Christopher B Granger, ${ }^{5}$ Stephan Windecker, ${ }^{6}$ Amit N Vora, ${ }^{7}$ \\ Dragos Vinereanu, ${ }^{8}$ Sigrun Halvorsen, ${ }^{9}$ Alexander Parkhomenko, ${ }^{10}$ \\ Roxana Mehran, ${ }^{11}$ John H Alexander, ${ }^{3}$ Shaun Goodman ${ }^{12,13}$
}

\begin{abstract}
- Additional supplemental material is published online only. To view, please visit the journal online (http://dx.doi.org/10. 1136/openhrt-2021-001892)

To cite: Welsh RC, Dehghani P, Lopes R, et al. Impact of prior oral anticoagulant use and outcomes on patients from secondary analysis in the AUGUSTUS trial. Open Heart 2022;9:e001892. doi:10.1136/ openhrt-2021-001892
\end{abstract}

Received 18 0ctober 2021 Accepted 11 January 2022

Check for updates

(C) Author(s) (or their employer(s)) 2022. Re-use permitted under CC BY-NC. No commercial re-use. See rights and permissions. Published by BMJ.

For numbered affiliations see end of article.

Correspondence to Dr Robert C. Welsh; Robert. Welsh@albertahealthservices.ca

\section{ABSTRACT}

Objective Managing antithrombotic therapy in patients with atrial fibrillation (AF) and an acute coronary syndrome (ACS) and/or percutaneous coronary intervention (PCl) is challenging and can be affected by prior oral anticoagulant (OAC) treatment. We examined the relationship between prior OAC use and outcomes in the AUGUSTUS trial. Methods This prespecified secondary analysis is from AUGUSTUS, an open-label, 2-by-2 factorial, RCT to evaluate the safety of apixaban versus vitamin $\mathrm{K}$ antagonist (VKA) and aspirin versus placebo in patients with $\mathrm{AF}$ and $\mathrm{ACS}$ and/or PCI. The primary endpoint, major or clinically relevant non-major bleeding and clinical outcomes were compared in patients receiving $(\mathrm{n}=2262)$ or not receiving $(n=2352)$ an OAC prior to enrolment. Results Patients with prior OAC use had more comorbidities, higher $\mathrm{CHA}_{2} \mathrm{DS}_{2}$-VASC and HAS-BLED scores, and were more likely enrolled following elective $\mathrm{PCl}$. There was no difference in major or clinically relevant non-major bleeding with or without prior OAC (30 days: $5.1 \%$ vs $5.9 \%$ (adjusted HR (aHR) $0.82,95 \% \mathrm{Cl} 0.63$ to 1.06); 180 days: $13.5 \%$ vs $13.5 \%$ (aHR $0.98,95 \% \mathrm{Cl} 0.83$ to 1.16)). Patients with prior OAC use had a lower risk of death or ischaemic events (30 days: $1.7 \%$ vs $2.8 \%$ (aHR $0.61,95 \% \mathrm{Cl} 0.41$ to 0.92 ); 180 days: $5.4 \%$ vs $7.6 \%$ (aHR $0.70,95 \% \mathrm{Cl} 0.55$ to 0.88 )). No interactions between randomised treatment (apixaban vs VKA, aspirin vs placebo) and prior OAC status were observed for outcomes, apart from apixaban (vs VKA) being associated with a lower risk of myocardial infarction with prior OAC use (180 days: $2.0 \%$ vs $3.7 \%$ (aHR $0.56,95 \% \mathrm{Cl} 0.33$ to 0.91() .

Conclusions In AUGUSTUS, prior OAC use was associated with fewer ischaemic events but not more bleeding. In patients with $\mathrm{AF}$ and $\mathrm{ACS}$ and/or undergoing $\mathrm{PCl}$, clinicians can be assured that the trial results can be applied to patients regardless of their prior OAC status. Trial registration number NCT02415400.

\section{INTRODUCTION}

Coronary artery disease and atrial fibrillation (AF) commonly coexist; approximately one

\section{Key questions}

What is already known about this subject?

- Managing antithrombotic therapy in patients with atrial fibrillation (AF) and an acute coronary syndrome (ACS) and/or percutaneous coronary intervention $(\mathrm{PCl})$ is challenging and can be affected by prior oral anticoagulant $(\mathrm{OAC})$ treatment.

What does this study add?

- No interactions between randomised treatment (apixaban vs vitamin $\mathrm{K}$ antagonists (VKA), aspirin vs placebo) and prior OAC status were observed for outcomes, apart from apixaban (vs VKA) being associated with a lower risk of myocardial infarction with prior OAC use.

How might this impact on clinical practice?

- In patients with $\mathrm{AF}$ and $\mathrm{ACS}$ and/or undergoing $\mathrm{PCI}$ clinicians can be assured that the results of the AUGUSTUS trial can be applied to these patients regardless of their prior OAC status when oral antithrombotic therapy is being prescribed at hospital discharge.

in five patients with $\mathrm{AF}$ have an acute coronary syndrome (ACS) and/or require percutaneous coronary intervention (PCI). ${ }^{1-3}$ A consistent finding across four landmark trials $^{4-7}$ and a subsequent meta-analysis ${ }^{8}$ is that dual antithrombotic therapy, particularly with a non-vitamin $\mathrm{K}$ antagonist oral anticoagulant (NOAC) and P2Y12 platelet inhibitor, is associated with a reduction in bleeding in this patient population compared with triple therapy with dual antiplatelet inhibition and an oral anticoagulant (OAC). The largest of these four studies that compared vitamin $\mathrm{K}$ antagonists (VKA) with an NOAC was the AUGUSTUS trial (An Open-Label, 2-by-2 Factorial, Randomised, Controlled Clinical Trial to Evaluate the Safety of Apixaban vs 
VKA and Aspirin vs Aspirin Placebo in Patients With AF and ACS and/or PCI). AUGUSTUS included patients with $\mathrm{AF}$ and either ACS or undergoing elective PCI and showed a lower risk of bleeding and hospitalisation and a similar risk of ischaemic events with an antithrombotic regimen consisting of apixaban and a P2Y12 inhibitor without aspirin compared with regimens that included VKAs, aspirin or both. ${ }^{6}$

Choosing the optimal antithrombotic regimen at hospital discharge is a challenging clinical scenario when patients with AF develop ACS and/or require PCI, especially when prior OAC therapy was used. First, physicians prefer continuing with already established therapies familiar to patients in order to mitigate potential risks of medication errors despite a change in patients' clinical scenario. Second, switching between OAC agents has been associated with an increase in thromboembolic and bleeding events. ${ }^{9-13}$ Third, different baseline characteristics may exist in those patients receiving an OAC prior to developing ACS or requiring elective PCI compared with those not treated with OAC, which may affect subsequent bleeding and ischaemic outcomes. ${ }^{1}$

The AUGUSTUS trial uniquely employed a 2-by-2 randomised factorial design (open-label apixaban vs VKA and blinded aspirin vs placebo), in contrast to the other randomised trials in which triple therapy (VKA, aspirin and P2Y12 inhibitor) was the standard of care comparison arm. This allowed assessment of the potential impact of prior OAC therapy without the confounding factor of triple therapy. We, therefore, performed a prespecified subgroup analysis of the AUGUSTUS trial to describe the patient characteristics, clinical events and potential interaction with randomised treatment arms comparing patients with or without prior OAC, with prior OAC separated into those receiving an NOAC or VKA.

\section{METHODS}

The AUGUSTUS trial design and results have been published. ${ }^{614}$ In brief, AUGUSTUS was an international, randomised, clinical trial with a 2-by-2 factorial design in which patients with AF and recent ACS and/or undergoing PCI and taking a P2Y12 inhibitor were factorially randomised to apixaban or VKA (open-label), and aspirin or aspirin placebo (double-blind) for 6 months. The current prespecified analyses explore outcomes according to whether patients were on OAC or not on OAC prior to enrolment in the trial. Prior OAC included participants receiving therapy prior to the index event and those started on therapy during the index event before randomisation. Patients provided written informed consent before inclusion in the study. There was no patient or public involvement in the design of the study.

\section{Outcome definition}

The primary outcome was the first occurrence of International Society on Thrombosis and Haemostasis (ISTH) major or clinically relevant non-major (CRNM) bleeding. ISTH major bleeding was defined as clinically overt bleeding with a haemoglobin drop of $\geq 2 \mathrm{~g} / \mathrm{dL}$, transfusion of $\geq 2$ units of packed red cells, or bleeding occurring at a critical site or resulting in death. CRNM bleeding was defined as overt bleeding that did not meet criteria for major bleeding and met $\geq 1$ of the following criteria: requires hospitalisation; requires physician-guided medical or surgical intervention or results in unscheduled contact with a physician (visit or telephone call); results in pain or impairment of daily activities; or results in a physician-guided change in antithrombotic therapy. Secondary efficacy outcomes included the composite of death or hospitalisation, and the composite of death or ischaemic events (composite of stroke, myocardial infarction, stent thrombosis (definite or probable) or urgent revascularisation). Other outcomes included ISTH major bleeding and individual components of the composite outcomes. Outcomes were adjudicated according to standard definitions by an independent committee blinded to treatment assignment.

\section{Statistical analyses}

Baseline characteristics including demographics, comorbidities, and index event are presented by prior OAC status. Additionally, patients with prior OAC use are subdivided by type of anticoagulant (VKA or NOAC). For patients who reported more than 1 type of anticoagulant, the most recent type is used to group subjects in VKA or NOAC groups. Continuous variables are summarised as median or means and quartiles or SD. Categorical variables are reported as frequencies and percentages. Wilcoxon, t-test, and $\chi^{2}$ tests were used to compare patients with and without prior OAC use.

For each endpoint, Kaplan-Meier estimates at 30 days and 180 days and number of patients with events are presented by prior OAC status. Unadjusted HRs and 95\% CIs were derived using a Cox proportional hazards model with prior OAC status as the only covariate. Adjustment variables used to derive adjusted HRs (AHRs) were: age, sex, race, hypertension, heart failure, diabetes, prior stroke, transient ischaemic attack (TIA) or thromboembolism, qualifying index event and time from index event to randomisation. Separate models were used to estimate the HRs at 30 days and 180 days. Models used to estimate HRs at 30 days included events from randomisation up to 30 days. Models used to estimate HRs at 180 days included events from randomisation up to 180 days. In a separate analysis, patients on prior OAC were divided by type of $\mathrm{OAC}$ and HRs were derived comparing prior NOAC and prior VKA vs no OAC.

\section{Randomised comparisons by prior OAC status}

For each endpoint, Kaplan-Meier estimates at 30 days and 180 days and number of patients with events are presented by randomised arm and prior OAC. Separate tables for the 2 factorial randomised comparisons are presented: apixaban versus warfarin and aspirin vs placebo. Additionally, 
descriptive results for the four treatment combinations (apixaban +aspirin, apixaban +placebo, warfarin +aspirin and warfarin + placebo) are presented.

HRs and $95 \%$ CIs comparing randomised treatments were derived from Cox proportional hazards models including prior OAC status, randomised treatment and their interaction. Similar analyses dividing the patients with prior OAC use by type of OAC are presented. The proportional hazard assumption was tested in all Cox models using scaled Schoenfeld residuals without clinically relevant deviations observed. All analyses were performed at Duke Clinical Research Institute using SAS System V.9.4 (TS1M6) (SAS Institute).

\section{RESULTS}

Of 4614 patients enrolled in the trial, 2262 (49\%) had prior OAC use and $2352(50.1 \%)$ did not. Patients with prior OAC use were older, more likely to be male, and have a history of hypertension, diabetes, congestive heart failure, stroke, TIA and thromboembolism, translating into higher $\mathrm{CHA}_{2} \mathrm{DS}_{2}-\mathrm{VAS}_{\mathrm{C}}$ and HAS-BLED scores (table 1). The prior OAC group was further separated into those on prior NOAC or VKA with baseline characteristics shown in the first 2 columns of table 1 . The most common qualifying events in the prior OAC and non-prior OAC groups were elective PCI and PCI due to ACS, respectively (table 1 ). OAC use before the index event was $66.5 \%$ among those with prior OAC use, with the remaining patients starting simultaneously with the index event, but prior to randomisation. Prior OAC use included VKA in $46 \%$ and NOAC in 54\% (online supplemental table 1).

\section{Prior OAC Compared with No OAC}

Prior OAC users and those with no prior OAC use had similar rates of the primary outcome of ISTH major or CRNM bleeding at 30 days (5.1\% vs $5.9 \%$; aHR 0.82 , $95 \%$ CI 0.63 to 1.06$)$ and 180 days (13.5\% vs $13.5 \%$; aHR $0.98,95 \%$ CI 0.83 to 1.16 ). Secondary safety outcome rates were also similar between groups. All-cause death or ischaemic events were lower in those with prior OAC use at 30 days $(1.7 \%$ vs $2.8 \%$; aHR $0.61,95 \%$ CI 0.41 to $0.92)$ and 180 days $(5.4 \%$ vs $7.6 \%$; aHR $0.70,95 \% \mathrm{CI}$ 0.55 to 0.88 ). Cardiovascular deaths at 180 days were lower with prior OAC use $(1.9 \%$ vs $2.9 \%$; aHR 0.61 , $95 \%$ CI 0.42 to 0.90 ). The remainder of secondary efficacy outcomes were numerically lower in the prior OAC group (table 2A). The outcomes comparing patients on prior NOAC with no prior OAC and prior VKA with no prior OAC are presented in table 2B.

\section{Apixaban versus VKA randomisation}

For the primary endpoint, there was no interaction between prior OAC status and randomised comparison between apixaban or VKA, with apixaban associated with lower rates of ISTH major/CRNM bleeding (table 3A). Similar trends were seen in secondary endpoints with the exception of myocardial infarction where an interaction was demonstrated. Myocardial infarction was reduced at 30 days with apixaban (apixaban $0.51 \%$ vs VKA $1.41 \%$; HR $0.36,95 \%$ CI 0.12 to 0.92 ) and 180 days (apixaban $1.98 \%$ vs VKA $3.65 \%$; HR 0.55 , 95\% CI 0.33 to 0.91 ) compared with warfarin in those with prior OAC use with no difference in myocardial infarction in those not on prior OAC.

\section{Aspirin versus aspirin placebo randomisation}

There was no interaction between prior OAC status and aspirin compared with aspirin placebo in the randomised arms for any endpoint (table 3B). The incidence of the primary outcome at 30 days in patients with prior OAC use was $7.1 \%$ with aspirin compared with $2.9 \%$ with placebo (HR 2.49, 95\% CI 1.65 to 3.75), and in those with no prior OAC use was $7.8 \%$ with aspirin compared with $4.0 \%$ with placebo (HR $1.98,95 \%$ CI 1.38 to 2.83 ). The incidence of the primary outcome at 180 days in patients with prior OAC use was $17.0 \%$ with aspirin compared with $9.6 \%$ with placebo (HR 1.91, 95\% CI 1.50 to 2.44), and in those with no prior OAC use was $17.3 \%$ with aspirin compared with $9.5 \%$ with placebo (HR 1.88, 95\% CI 1.48 to 2.39).

\section{Prior NOAC, prior VKA and no prior OAC comparison by randomised arm}

The Kaplan-Meier event rates and HRs with assessment for interaction between those with no prior OAC, prior NOAC and prior VKA are presented for apixaban compared with VKA and aspirin compared with placebo in figure 1 (online supplemental tables $2 \mathrm{~A}$ and $2 \mathrm{~B}$ ). There was no interaction found for the primary endpoint at 30 days or 180 days between no prior OAC, prior NOAC and prior VKA with either the randomisation to apixaban compared with VKA or aspirin compared with placebo (online supplemental tables 2A and 2B). Myocardial infarction occurred less frequently in those previously on an NOAC randomised to apixaban vs VKA at 30 days $(0.48 \%$ vs $2.01 \%$; HR $0.24,95 \%$ CI 0.16 to 0.84$)$ and 180 days $(1.47 \%$ vs $3.89 \%$; HR $0.82,95 \%$ CI 0.17 to 0.77 ) (figure 1 and online supplemental table 2A).

\section{DISCUSSION}

In this prespecified subgroup analysis of the AUGUSTUS trial, we explored patient characteristics, clinical events and potential interaction with randomised treatment arms comparing patients with or without prior OAC use. The main findings of this study are (1) despite increased comorbidities and associated higher HAS-BLED scores, patients on prior OAC had similar 30-day and 180-day incidence of the primary endpoint of ISTH major or CRNM bleeding, including after adjustment for these and other baseline characteristic differences; (2) apixaban was associated with lower rates of the primary endpoint compared with VKA regardless of prior OAC use and (3) aspirin was associated with a higher incidence of the primary endpoint compared with placebo regardless of prior OAC use. Accordingly, clinicians can be assured 
Table 1 Baseline characteristics by prior oral anticoagulation status at randomisation

\begin{tabular}{|c|c|c|c|c|c|}
\hline \multirow[b]{2}{*}{ Characteristic } & \multicolumn{3}{|l|}{ Prior OAC } & \multirow{2}{*}{$\begin{array}{l}\text { No prior OAC } \\
(\mathrm{N}=2352)\end{array}$} & \multirow[b]{2}{*}{$\mathrm{P}$ value $†$} \\
\hline & $\begin{array}{l}\text { NOAC } \\
(\mathrm{N}=1227)\end{array}$ & $\begin{array}{l}\text { VKA } \\
(N=1033)\end{array}$ & $\begin{array}{l}\text { Any OAC* } \\
(\mathrm{N}=2262)\end{array}$ & & \\
\hline $\begin{array}{l}\text { Age, median (25th, } 75 \text { th), } \\
\text { years }\end{array}$ & $71,64-77$ & $71,65-77$ & $71,65-77$ & $70,64-77$ & 0.040 \\
\hline Female sex, no (\%) & $336(27.4)$ & $276(26.7)$ & $613(27.1)$ & $724(30.8)$ & 0.006 \\
\hline Race, no/No (\%) & & & & & 0.018 \\
\hline White & $1120 / 1208(92.7)$ & 960/1031 (93.1) & 2082/2241 (92.9) & 2102/2316 (90.8) & \\
\hline Black & $14 / 1208(1.2)$ & 12/1031 (1.2) & 26/2241 (1.2) & $33 / 2316(1.4)$ & \\
\hline Asian & $35 / 1208(2.9)$ & $32 / 1031(3.1)$ & $67 / 2241(3.0)$ & 73/2316 (3.2) & \\
\hline Other & $39 / 1208(3.2)$ & $27 / 1031(2.6)$ & $66 / 2241(2.9)$ & $108 / 2316(4.7)$ & \\
\hline $\begin{array}{l}\text { Serum creatinine, median } \\
\text { (25th, } 75 \mathrm{th}), \mathrm{mg} / \mathrm{dL}\end{array}$ & $1.0,0.9-1.2$ & $1.0,0.9-1.2$ & $1.0,0.9-1.2$ & $1.0,0.9-1.2$ & 0.020 \\
\hline $\begin{array}{l}\text { Serum creatinine, no/ } \\
\text { No (\%) }\end{array}$ & & & & & 0.56 \\
\hline$<1.5 \mathrm{mg} / \mathrm{dL}$ & $1114 / 1210(92.1 \%)$ & 938/1024 (91.6\%) & 2054/2236 (91.9\%) & 2098/2296 (91.4\%) & \\
\hline$\geq 1.5 \mathrm{mg} / \mathrm{dL}$ & $96 / 1210(7.9 \%)$ & $86 / 1024(8.4 \%)$ & $182 / 2236(8.1 \%)$ & 198/2296 (8.6\%) & \\
\hline $\begin{array}{l}\mathrm{CHA}_{2} \mathrm{DS}_{2} \text {-VASc score, } \\
\text { mean (SD) }\end{array}$ & $4.0(1.5)$ & $4.1(1.6)$ & $4.0(1.5)$ & $3.8(1.6)$ & $<0.001$ \\
\hline $\begin{array}{l}\text { HAS-BLED score, mean } \\
\text { (SD) }\end{array}$ & $2.9(0.9)$ & $2.9(1.0)$ & $2.9(1.0)$ & $2.8(0.9)$ & $<0.001$ \\
\hline $\begin{array}{l}\text { Hypertension leading to } \\
\text { medication use, no (\%) }\end{array}$ & $1104(90.0 \%)$ & $923(89.4 \%)$ & $2029(89.7 \%)$ & 2044 (86.9\%) & 0.003 \\
\hline Heart failure, no (\%) & $546(44.5 \%)$ & $510(49.4 \%)$ & $1056(46.7 \%)$ & $917(39.0 \%)$ & $<0.001$ \\
\hline Diabetes mellitus, no (\%) & $472(38.5 \%)$ & 399 (38.6\%) & $872(38.5 \%)$ & 806 (34.3\%) & 0.003 \\
\hline $\begin{array}{l}\text { Stroke, TIA, or } \\
\text { thromboembolism, no/ } \\
\text { No (\%) }\end{array}$ & $171 / 1218(14.0 \%)$ & $173 / 1027(16.8 \%)$ & $344 / 2247(15.3 \%)$ & 289/2334 (12.4\%) & 0.004 \\
\hline $\begin{array}{l}\text { Concomitant P2Y12 } \\
\text { inhibitor, no (\%) }\end{array}$ & & & & & $<0.001$ \\
\hline Clopidogrel & $1123(91.5 \%)$ & 985 (95.4\%) & $2110(93.3 \%)$ & $2055(87.4 \%)$ & \\
\hline Ticagrelor & $66(5.4 \%)$ & $25(2.4 \%)$ & $91(4.0 \%)$ & $189(8.0 \%)$ & \\
\hline Prasugrel & $15(1.2 \%)$ & $6(0.6 \%)$ & $21(0.9 \%)$ & $30(1.3 \%)$ & \\
\hline None & $23(1.9 \%)$ & 17 (1.6\%) & 40 (1.8\%) & 78 (3.3\%) & \\
\hline $\begin{array}{l}\text { Qualifying index event, no/ } \\
\text { No (\%) }\end{array}$ & & & & & $<0.001$ \\
\hline $\mathrm{ACS}$ and $\mathrm{PCl}$ & 418/1223 (34.2\%) & 294/1031 (28.5\%) & 712/2256 (31.6\%) & 1002/2339 (42.8\%) & \\
\hline Medically managed ACS & $216 / 1223$ (17.7\%) & $305 / 1031$ (29.6\%) & $521 / 2256(23.1 \%)$ & $576 / 2339(24.6 \%)$ & \\
\hline Elective PCl & $589 / 1223(48.2 \%)$ & 432/1031 (41.9\%) & $1023 / 2256(45.3 \%)$ & $761 / 2339(32.5 \%)$ & \\
\hline $\begin{array}{l}\text { Days from ACS or PCl to } \\
\text { randomisation, mean (SD) }\end{array}$ & $6.7(4.3)$ & $7.0(4.2)$ & $6.8(4.3)$ & $6.4(4.1)$ & 0.001 \\
\hline $\begin{array}{l}\text { On OAC prior to index } \\
\text { event, no/No (\%) }\end{array}$ & 827/1227 (67.4\%) & 677/1033 (65.5\%) & 1505/2262 (66.5\%) & - & - \\
\hline
\end{tabular}

For patients reporting more than one type of anticoagulant, the most recent type is used.

${ }^{*}$ Two patients reported prior oral anticoagulant use but information about the type of anticoagulant was not reported; they were included in the 'any OAC' group.

†P value compares 'any OAC' versus 'no prior OAC' columns.

ACS, acute coronary syndrome; NOAC, non-vitamin K antagonist oral anticoagulant; OAC, oral anticoagulant; PCl, percutaneous coronary intervention; TIA, transient ischaemic attack; VKA, vitamin $\mathrm{K}$ antagonist. 
Table 2A Association between prior oral anticoagulant use and endpoints

\begin{tabular}{|c|c|c|c|c|c|c|}
\hline \multirow[b]{2}{*}{ Endpoint } & \multicolumn{2}{|l|}{ Prior OAC } & \multicolumn{2}{|l|}{ Unadjusted } & \multicolumn{2}{|l|}{ Adjusted* } \\
\hline & $\begin{array}{l}\text { Yes } \\
\text { KM\% (events) }\end{array}$ & $\begin{array}{l}\text { No } \\
\text { KM\% (events) }\end{array}$ & $\begin{array}{l}\text { HR }(95 \% \mathrm{Cl}) \\
\text { Prior OAC Yes vs No }\end{array}$ & $P$ value & $\begin{array}{l}\text { HR }(95 \% \mathrm{Cl}) \\
\text { Prior OAC Yes vs No }\end{array}$ & $P$ value \\
\hline \multicolumn{7}{|c|}{$\begin{array}{l}\text { Primary endpoint } \\
\text { ISTH major/CRNM bleeding }\end{array}$} \\
\hline At 30 days & $5.1(111)$ & $5.9(131)$ & 0.87 (0.67 to 1.12$)$ & 0.27 & 0.82 (0.63 to 1.06$)$ & 0.13 \\
\hline At 180 days & $13.5(282)$ & $13.5(288)$ & 1.004 (0.85 to 1.18$)$ & 0.96 & 0.98 (0.83 to 1.16$)$ & 0.80 \\
\hline \multicolumn{7}{|c|}{ ISTH major bleeding } \\
\hline At 30 days & $1.2(30)$ & $1.8(39)$ & 0.79 (0.49 to 1.27$)$ & 0.33 & 0.65 (0.39 to 1.07$)$ & 0.093 \\
\hline At 180 days & $4.2(86)$ & $4.3(90)$ & $1.00(0.74$ to 1.34$)$ & 0.99 & 0.90 (0.66 to 1.22$)$ & 0.48 \\
\hline \multicolumn{7}{|c|}{ Intracranial bleeding } \\
\hline At 30 days & $0.00(0)$ & $0.2(4)$ & - & - & - & - \\
\hline At 180 days & $0.5(10)$ & $0.4(9)$ & 1.13 (0.46 to 2.79$)$ & 0.79 & 0.96 (0.38 to 2.40$)$ & 0.92 \\
\hline \multicolumn{7}{|c|}{$\begin{array}{l}\text { Definite/probable stent } \\
\text { thrombosis }\end{array}$} \\
\hline At 30 days & $0.5(11)$ & $0.7(16)$ & 0.71 (0.33 to 1.53 ) & 0.38 & 0.73 (0.33 to 1.59$)$ & 0.43 \\
\hline At 180 days & $0.6(14)$ & $0.8(18)$ & 0.801 (0.40 to 1.61$)$ & 0.53 & 0.81 (0.40 to 1.66$)$ & 0.57 \\
\hline \multicolumn{7}{|c|}{$\begin{array}{l}\text { All-cause death or } \\
\text { rehospitalisaAtion }\end{array}$} \\
\hline At 30 days & $9.2(208)$ & $10.8(250)$ & $0.86(0.71$ to 1.030$)$ & 0.099 & 0.86 (0.71 to 1.04$)$ & 0.11 \\
\hline At 180 days & $26.3(585)$ & $25.4(580)$ & 1.04 (0.93 to 1.17$)$ & 0.46 & 1.02 (0.90 to 1.14$)$ & 0.80 \\
\hline \multicolumn{7}{|c|}{$\begin{array}{l}\text { All-cause death or ischaemic } \\
\text { event }\end{array}$} \\
\hline At 30 days & $1.7(38)$ & $2.8(65)$ & 0.60 (0.40 to 0.90$)$ & 0.012 & 0.61 (0.41 to 0.92) & 0.019 \\
\hline At 180 days & $5.4(119)$ & 7.6(171) & 0.72 (0.57 to 0.91$)$ & 0.006 & 0.70 (0.55 to 0.88$)$ & 0.003 \\
\hline \multicolumn{7}{|c|}{ Cardiovascular death } \\
\hline At 30 days & $0.6(13)$ & $0.9(20)$ & 0.67 (0.33 to 1.35$)$ & 0.26 & 0.70 (0.34 to 1.42$)$ & 0.32 \\
\hline At 180 days & $1.9(43)$ & $2.9(67)$ & 0.67 (0.46 to 0.98$)$ & 0.04 & 0.61 (0.42 to 0.90$)$ & 0.013 \\
\hline \multicolumn{7}{|l|}{ Stroke } \\
\hline At 30 days & $0.2(4)$ & $0.4(9)$ & 0.46 (0.14 to 1.49$)$ & 0.19 & 0.53 (0.16 to 1.74$)$ & 0.29 \\
\hline At 180 days & $0.8(16)$ & $1.0(23)$ & 0.71 (0.38 to 1.35) & 0.29 & 0.74 (0.39 to 1.43$)$ & 0.37 \\
\hline \multicolumn{7}{|c|}{ Myocardial infarction } \\
\hline At 30 days & $0.9(21)$ & $1.7(39)$ & 0.55 (0.33 to 0.94$)$ & 0.029 & 0.59 (0.34 to 1.01$)$ & 0.053 \\
\hline At 180 days & $2.8(61)$ & $4.0(89)$ & 0.72 (0.52 to 0.99) & 0.044 & 0.73 (0.53 to 1.02 ) & 0.065 \\
\hline
\end{tabular}

HRs in the 'at 30 days' rows include events from randomisation to 30 days. HRs in the 'at 180 days' rows include events from randomisation to 180 days.

${ }^{*}$ Adjusted by age, sex, race, hypertension, heart failure, diabetes, prior stroke, TIA or thromboembolism, qualifying index event and time from index event to randomisation.

CRNM, clinically relevant non-major; ISTH, International Society on Thrombosis and Haemostasis; KM, Kaplan-Meier; OAC, oral anticoagulation; TIA, transient ischaemic attack.

that the results of the AUGUSTUS trial can be applied to these patients regardless of their prior OAC status when oral antithrombotic therapy is being prescribed at hospital discharge.

In AUGUSTUS, OAC use prior to enrolment was more common in patients with comorbidities and those enrolled following elective PCI. Despite increased comorbidities and the associated increased HAS-BLED scores in patients with prior OAC use, this group did not have an increased 30-day or 180-day incidence of the combined primary endpoint (ISTH major or CRNM bleeding) or the secondary safety endpoint (ISTH major bleeding or intracranial bleeding) in the unadjusted or adjusted analysis. Prior OAC use was associated with fewer ischaemic events, with the combined outcome of all-cause death or ischaemic events (composite of stroke, myocardial infarction, stent thrombosis (definite or probable), or urgent revascularisation) reduced by $39 \%$ at 30 days and $30 \%$ at 180 days after adjusting for baseline differences. Further stratification of prior OAC group into those 
Table 2B Association between type of prior oral anticoagulant use and endpoints

\begin{tabular}{|c|c|c|c|c|c|c|}
\hline \multirow[b]{2}{*}{ Endpoint } & \multirow{2}{*}{$\begin{array}{l}\text { Prior NOAC } \\
\text { KM\% } \\
\text { (events) }\end{array}$} & \multirow{2}{*}{$\begin{array}{l}\text { Prior VKA } \\
\text { KM\% } \\
\text { (events) }\end{array}$} & \multirow{2}{*}{$\begin{array}{l}\text { No prior OAC } \\
\text { KM\% } \\
\text { (events) }\end{array}$} & \multirow{2}{*}{$\begin{array}{l}\text { NOAC vs no OAC } \\
\text { Adj. HR }(95 \% \mathrm{Cl})^{*}\end{array}$} & \multirow{2}{*}{$\begin{array}{l}\text { VKA vs no OAC } \\
\text { Adj. HR }(95 \% \mathrm{Cl})^{*}\end{array}$} & \multirow[b]{2}{*}{$P$ value } \\
\hline & & & & & & \\
\hline \multicolumn{7}{|c|}{$\begin{array}{l}\text { Primary endpoint } \\
\text { ISTH major/CRNM } \\
\text { bleeding }\end{array}$} \\
\hline At 30 days & $5.1(60)$ & $5.1(51)$ & $5.9(131)$ & 0.80 (0.58 to 1.10$)$ & 0.84 (0.60 to 1.17$)$ & 0.33 \\
\hline \multicolumn{7}{|c|}{ ISTH major bleeding } \\
\hline At 30 days & $1.1(13)$ & $1.7(17)$ & $1.8(39)$ & $0.48(0.24$ to 0.95$)$ & 0.84 (0.47 to 1.51$)$ & 0.11 \\
\hline At 180 days & $3.8(41)$ & $4.7(45)$ & $4.3(90)$ & 0.78 (0.53 to 1.15$)$ & 1.02 (0.71 to 1.48$)$ & 0.39 \\
\hline \multicolumn{7}{|c|}{ Intracranial bleeding } \\
\hline At 30 days & $0.7(8)$ & $0.3(3)$ & $0.7(16)$ & 0.92 (0.39 to 2.17$)$ & 0.47 (0.14 to 1.63$)$ & 0.49 \\
\hline At 180 days & $0.7(9)$ & $0.5(5)$ & $0.8(18)$ & 0.92 (0.41 to 2.08$)$ & 0.67 (0.25 to 1.82$)$ & 0.73 \\
\hline \multicolumn{7}{|c|}{$\begin{array}{l}\text { All-cause death or } \\
\text { rehospitalisation }\end{array}$} \\
\hline At 30 days & $10.1(124)$ & $8.1(83)$ & $10.8(250)$ & 0.92 (0.74 to 1.15$)$ & 0.77 (0.60 to 0.99$)$ & 0.12 \\
\hline At 180 days & $27.6(332)$ & $24.6(251)$ & $25.4(580)$ & 1.07 (0.93 to 1.22$)$ & 0.95 (0.82 to 1.11$)$ & 0.40 \\
\hline \multicolumn{7}{|c|}{$\begin{array}{l}\text { All-cause death or } \\
\text { ischaemic event }\end{array}$} \\
\hline At 30 days & $2.0(25)$ & $1.3(13)$ & $2.8(65)$ & 0.74 (0.46 to 1.18$)$ & $0.46(0.25$ to 0.85$)$ & 0.03 \\
\hline At 30 days & $0.2(2)$ & $0.2(2)$ & $0.4(9)$ & 0.48 (0.10 to 2.26$)$ & 0.58 (0.12 to 2.76$)$ & 0.57 \\
\hline At 180 days & $1.0(11)$ & $0.5(5)$ & $1.0(23)$ & 1.01 (0.49 to 2.11) & 0.47 (0.185 to 1.25$)$ & 0.29 \\
\hline \multicolumn{7}{|c|}{ Myocardial infarction } \\
\hline At 30 days & $1.2(15)$ & $0.6(6)$ & $1.7(39)$ & 0.76 (0.41 to 1.39$)$ & 0.37 (0.16 to 0.89$)$ & 0.08 \\
\hline At 180 days & $2.7(32)$ & $2.9(29)$ & $4.0(89)$ & 0.73 (0.48 to 1.09 ) & 0.74 (0.48 to 1.13$)$ & 0.18 \\
\hline
\end{tabular}

HRs in the 'at 30 days' rows include events from randomisation to 30 days. HRs in the 'at 180 days' rows include events from randomisation to 180 days.

*Adjusted by age, sex, race, hypertension, heart failure, diabetes, prior stroke, TIA or thromboembolism, qualifying index event and time from index event to randomisation.

CRNM, clinically relevant non-major; ISTH, International Society on Thrombosis and Haemostasis; KM, Kaplan-Meier; NOAC, non-vitamin K antagonist oral anticoagulant; TIA, transient ischaemic attack; VKA, vitamin K antagonist.

treated previously with an NOAC or VKA confirmed no difference in the primary endpoint, although those with a prior NOAC compared with no prior OAC had a $52 \%$ lower risk of ISTH major bleeding at 30 days which was not seen in those on prior VKA compared with NOAC (table 2B). The difference in all-cause death or ischaemic events at 30 days was $64 \%$ lower in the prior VKA group compared with the no prior OAC group and $35 \%$ lower at 180 days.
The most robust comparison in this current analysis is between the randomised arms of the study. The primary endpoint of ISTH major or CRNM bleeding at 180 days was reduced by $30 \%$ with apixaban compared with VKA in both those with or without prior OAC use at the time of randomisation (table 3A). Similarly, randomisation to aspirin compared with placebo was associated with a doubling of the primary endpoint in both those with and without prior OAC therapy. These findings were 
Table 3A Association between randomised treatment (apixaban vs VKA) and endpoints by prior oral anticoagulant status

\begin{tabular}{|c|c|c|c|c|c|c|c|}
\hline \multirow[b]{2}{*}{ Endpoint } & \multicolumn{3}{|c|}{ Prior oral anticoagulant=Yes } & \multicolumn{3}{|c|}{ Prior oral anticoagulant=No } & \multirow[b]{2}{*}{$\begin{array}{l}\text { Interaction } \\
\text { p value }\end{array}$} \\
\hline & $\begin{array}{l}\text { Apixaban } \\
\text { KM \% } \\
\text { (events) }\end{array}$ & $\begin{array}{l}\text { VKA } \\
\text { KM \% } \\
\text { (events) }\end{array}$ & $\begin{array}{l}\text { HR }^{\star}(95 \% \mathrm{Cl}) \\
\text { Apixaban vs VKA }\end{array}$ & $\begin{array}{l}\text { Apixaban } \\
\text { KM \% } \\
\text { (events) }\end{array}$ & $\begin{array}{l}\text { VKA } \\
\text { KM \% } \\
\text { (events) }\end{array}$ & $\begin{array}{l}\text { HR }^{*}(95 \% \mathrm{Cl}) \\
\text { Apixaban vs VKA }\end{array}$ & \\
\hline \multicolumn{8}{|c|}{$\begin{array}{l}\text { Primary endpoint } \\
\text { ISTH major/CRNM } \\
\text { bleeding }\end{array}$} \\
\hline At 30 days & $4.4(51)$ & $5.7(58)$ & 0.77 (0.53 to 1.12$)$ & $4.2(45)$ & $7.5(86)$ & 0.56 (0.39 to 0.80$)$ & 0.23 \\
\hline At 180 days & $11.3(127)$ & $15.6(152)$ & 0.70 (0.56 to 0.89 ) & $10.9(113)$ & $15.6(173)$ & 0.67 (0.53 to 0.85$)$ & 0.787 \\
\hline \multicolumn{8}{|c|}{ ISTH major bleeding } \\
\hline At 30 days & $1.0(12)$ & $1.7(17)$ & $0.62(0.30$ to 1.29$)$ & $1.3(14)$ & $2.1(24)$ & 0.63 (0.32 to 1.21$)$ & 0.98 \\
\hline At 180 days & $3.4(38)$ & $4.7(45)$ & 0.70 (0.45 to 1.07$)$ & $3.0(31)$ & $5.2(57)$ & 0.58 (0.37 to 0.89$)$ & 0.54 \\
\hline \multicolumn{8}{|c|}{ Intracranial bleeding } \\
\hline At 30 days & $0.0(0)$ & $0.0(0)$ & --- & $0.1(1)$ & $0.3(3)$ & 0.36 (0.04 to 3.49 ) & --- \\
\hline At 180 days & $0.2(2)$ & $0.8(7)$ & 0.25 (0.05 to 1.18$)$ & $0.3(3)$ & $0.5(6)$ & 0.53 (0.13 to 2.11$)$ & 0.47 \\
\hline \multicolumn{8}{|c|}{$\begin{array}{l}\text { Definite/probable } \\
\text { stent thrombosis }\end{array}$} \\
\hline At 30 days & $0.3(3)$ & $0.8(8)$ & 0.33 (0.09 to 1.26$)$ & $0.7(8)$ & $0.7(8)$ & 1.11 (0.42 to 2.95$)$ & 0.16 \\
\hline At 180 days & $0.3(4)$ & $1.0(10)$ & 0.36 (0.11 to 1.14$)$ & $0.9(10)$ & $0.7(8)$ & 1.38 (0.55 to 3.50$)$ & 0.07 \\
\hline \multicolumn{8}{|c|}{$\begin{array}{l}\text { All-cause death or } \\
\text { Rehospitalisation }\end{array}$} \\
\hline At 30 days & $8.7(103)$ & $9.9(105)$ & 0.86 (0.66 to 1.13$)$ & $9.5(105)$ & $11.9(145)$ & 0.80 (0.62 to 1.03$)$ & 0.69 \\
\hline 180 days & 24.9 (293) & 27.9 (292) & 0.86 (0.73 to 1.01$)$ & $22.9(247)$ & $27.8(333)$ & 0.80 (0.68 to 0.94$)$ & 0.49 \\
\hline \multicolumn{8}{|c|}{$\begin{array}{l}\text { All-cause death or } \\
\text { Ischaemic event }\end{array}$} \\
\hline At 30 days & $1.2(14)$ & $2.3(24)$ & 0.52 (0.27 to 1.00$)$ & $2.4(26)$ & $3.2(39)$ & 0.73 (0.45 to 1.20$)$ & 0.41 \\
\hline At 180 days & $4.9(58)$ & $5.9(61)$ & 0.86 (0.60 to 1.22 ) & $7.9(83)$ & $7.3(88)$ & 1.04 (0.77 to 1.42$)$ & 0.41 \\
\hline \multicolumn{8}{|c|}{ Cardiovascular death } \\
\hline At 30 days & $0.4(5)$ & $0.8(8)$ & 0.56 (0.18 to 1.71$)$ & $0.7(8)$ & $1.0(12)$ & 0.74 (0.30 to 1.80$)$ & 0.70 \\
\hline At 180 days & $2.0(23)$ & $1.9(20)$ & 1.07 (0.59 to 1.93$)$ & $3.0(33)$ & $2.8(34)$ & 1.07 (0.66 to 1.73 ) & 0.99 \\
\hline \multicolumn{8}{|l|}{ Stroke } \\
\hline At 30 days & $0.1(1)$ & $0.3(3)$ & 0.30 (0.03 to 2.86$)$ & $0.3(3)$ & $0.5(6)$ & $0.55(0.14-$ to 2.21$)$ & 0.65 \\
\hline At 180 days & $0.6(7)$ & $0.9(9)$ & 0.69 (0.26 to 1.86$)$ & $0.6(6)$ & $1.4(17)$ & 0.39 (0.15 to 0.99$)$ & 0.40 \\
\hline \multicolumn{8}{|c|}{ Myocardial infarction } \\
\hline At 30 days & $0.5(6)$ & $1.4(15)$ & 0.36 (0.14 to 0.92$)$ & $1.6(18)$ & $1.7(21)$ & 0.94 (0.50 to 1.77 ) & 0.09 \\
\hline At 180 days & $2.0(23)$ & $3.7(38)$ & 0.56 (0.33 to 0.91$)$ & $4.7(48)$ & $3.4(41)$ & 1.30 (0.86 to 1.97$)$ & 0.01 \\
\hline
\end{tabular}

*HRs in the 'at 30 days' rows include events from randomisation to 30 days. HRs in the 'at 180 days' rows include events from randomisation to 180 days.

CRNM, clinically relevant non-major; ISTH, International Society on Thrombosis and Haemostasis; KM, Kaplan-Meier; VKA, vitamin K antagonist.

consistent whether the prior OAC was an NOAC or VKA. Myocardial infarction was the only secondary endpoint with a significant interaction in events with patients on a prior NOAC having a $70 \%$ lower incidence at 30 days and a $64 \%$ lower incidence at 180 days when randomised to apixaban compared with VKA. However, we did not adjust for multiple comparisons, including for individual endpoints such as myocardial infarction, which was not part of the primary outcome.
Several large-scale observational studies and subgroup analyses have assessed the impact of initiating an NOAC or VKA in populations that were previously naive to OAC therapy or alternatively switching from VKA to an NOAC. ${ }^{3} 1012$ 15-17 An analysis from the French medicoadministrative databases demonstrated no difference in 90-day bleeding or thromboembolic complications in OAC-naïve matched patients initiated on VKA, dabigatran or rivaroxaban. ${ }^{15}$ Additionally, there was no 
Table 3В Association between randomised treatment (aspirin vs placebo) and endpoints by prior oral anticoagulant status

\begin{tabular}{|c|c|c|c|c|c|c|c|}
\hline \multirow[b]{2}{*}{ Endpoint } & \multicolumn{3}{|c|}{ Prior oral anticoagulant=Yes } & \multicolumn{3}{|c|}{ Prior oral anticoagulant=No } & \multirow[b]{2}{*}{$\begin{array}{l}\text { Interaction } \\
\text { p value }\end{array}$} \\
\hline & $\begin{array}{l}\text { Aspirin } \\
\text { KM \% } \\
\text { (events) }\end{array}$ & $\begin{array}{l}\text { Placebo } \\
\text { KM \% } \\
\text { (events) }\end{array}$ & $\begin{array}{l}\mathrm{HR}^{\star}(95 \% \mathrm{Cl}) \\
\text { Aspirin vs placebo }\end{array}$ & $\begin{array}{l}\text { Aspirin } \\
\text { KM \% } \\
\text { (events) }\end{array}$ & $\begin{array}{l}\text { Placebo } \\
\text { KM \% } \\
\text { (events) }\end{array}$ & $\begin{array}{l}\text { HR }^{\star}(95 \% \mathrm{Cl}) \\
\text { Aspirin vs } \\
\text { Placebo }\end{array}$ & \\
\hline \multicolumn{8}{|c|}{$\begin{array}{l}\text { Primary Endpoint } \\
\text { ISTH major/CRNM } \\
\text { bleeding }\end{array}$} \\
\hline At 30 days & $7.1(78)$ & $2.9(32)$ & 2.49 (1.65 to 3.76$)$ & $7.8(87)$ & $4.0(45)$ & 1.98 (1.38 to 2.83$)$ & 0.41 \\
\hline At 180 days & $17.0(179)$ & $9.6(100)$ & 1.91 (1.50 to 2.44$)$ & $17.3(185)$ & $9.5(101)$ & 1.88 (1.48 to 2.39$)$ & 0.93 \\
\hline \multicolumn{8}{|c|}{ ISTH major bleeding } \\
\hline At 30 days & $1.8(19)$ & $0.9(10)$ & 1.91 (0.89 to 4.12$)$ & $2.7(30)$ & $1.0(11)$ & 2.77 (1.39 to 5.52$)$ & 0.48 \\
\hline At 180 days & $4.8(49)$ & $3.3(34)$ & 1.50 (0.97 to 2.33$)$ & $5.5(58)$ & $3.0(31)$ & 1.93 (1.25 to 2.99$)$ & 0.43 \\
\hline \multicolumn{8}{|c|}{ Intracranial bleeding } \\
\hline At 30 days & $0.0(0)$ & $0.0(0)$ & --- & $0.2(2)$ & $0.2(2)$ & 1.01 (0.14 to 7.15$)$ & --- \\
\hline At 180 days & $0.3(3)$ & $0.6(6)$ & 0.51 (0.127 to 2.035$)$ & $0.5(5)$ & $0.4(4)$ & 1.29 (0.35 to 4.79$)$ & 0.34 \\
\hline \multicolumn{8}{|c|}{$\begin{array}{l}\text { Definite/Probable } \\
\text { stent thrombosis }\end{array}$} \\
\hline At 30 days & $0.4(4)$ & $0.6(7)$ & 0.57 (0.17 to 1.95$)$ & $0.4(4)$ & $1.0(12)$ & 0.33 (0.11 to 1.03$)$ & 0.52 \\
\hline At 180 days & $0.5(5)$ & $0.8(9)$ & 0.56 (0.19 to 1.66$)$ & $0.5(6)$ & $1.0(12)$ & $0.500(0.19$ to 1.33$)$ & 0.89 \\
\hline \multicolumn{8}{|c|}{$\begin{array}{l}\text { All-cause death or } \\
\text { rehospitalisation }\end{array}$} \\
\hline At 30 days & $9.9(111)$ & $8.6(97)$ & 1.15 (0.88 to 1.51$)$ & $11.7(136)$ & $9.8(114)$ & 1.20 (0.94 to 1.54$)$ & 0.81 \\
\hline At 180 days & 26.4 (292) & $26.2(293)$ & 1.01 (0.86 to 1.18$)$ & $27.0(307)$ & $23.9(273)$ & 1.16 (0.98 to 1.36$)$ & 0.24 \\
\hline \multicolumn{8}{|c|}{$\begin{array}{l}\text { All-cause death or } \\
\text { ischaemic event }\end{array}$} \\
\hline At 30 days & $1.4(16)$ & $2.0(22)$ & 0.73 (0.38 to 1.38$)$ & $2.2(25)$ & $3.4(40)$ & 0.62 (0.38 to 1.03$)$ & 0.71 \\
\hline At 180 days & $5.2(57)$ & $5.6(62)$ & 0.93 (0.65 to 1.33$)$ & $6.9(78)$ & $8.2(93)$ & 0.84 (0.62 to 1.13 ) & 0.66 \\
\hline \multicolumn{8}{|c|}{ Cardiovascular death } \\
\hline At 30 days & $0.7(8)$ & $0.4(5)$ & 1.60 (0.52 to 4.90$)$ & $0.5(6)$ & $1.2(14)$ & 0.43 (0.16 to 1.11$)$ & 0.079 \\
\hline At 180 days & $2.0(22)$ & $1.9(21)$ & 1.10 (0.61 to 1.98$)$ & $2.6(30)$ & $3.2(37)$ & 0.81 (0.50 to 1.32 ) & 0.45 \\
\hline \multicolumn{8}{|l|}{ Stroke } \\
\hline At 30 days & $0.1(1)$ & $0.3(3)$ & 0.33 (0.04 to 3.21$)$ & $0.5(6)$ & $0.3(3)$ & 2.00 (0.50 to 8.01 ) & 0.19 \\
\hline At 180 days & $0.7(8)$ & $0.8(8)$ & 1.00 (0.38 to 2.67$)$ & $1.1(12)$ & $1.0(11)$ & 1.10 (0.48 to 2.48$)$ & 0.89 \\
\hline \multicolumn{8}{|c|}{ Myocardial infarction } \\
\hline At 30 days & $0.6(7)$ & $1.2(14)$ & 0.50 (0.20 to 1.24$)$ & $1.1(13)$ & $2.2(26)$ & 0.50 (0.26 to 0.97 ) & 0.99 \\
\hline At 180 days & $2.4(26)$ & $3.1(35)$ & $0.75(0.45$ to 1.23$)$ & $3.7(41)$ & $4.4(48)$ & 0.85 (0.56 to 1.30$)$ & 0.69 \\
\hline
\end{tabular}

*HRs in the 'at 30 days' rows include events from randomisation to 30 days. HRs in the 'at 180 days' rows include events from randomisation to 180 days.

CRNM, clinically relevant non-major; ISTH, International Society on Thrombosis and Haemostasis; KM, Kaplan-Meier; VKA, vitamin K antagonist.

difference in bleeding outcomes in patients sustained on VKA $(n=10705)$ and those switched $(n=6705)$ either to dabigatran or rivaroxaban. ${ }^{16}$

Consistent with the current analysis, prior OAC users in the RE-DUAL PCI (Randomised Evaluation of Dual Antithrombotic Therapy With Dabigatran vs Triple Therapy With Warfarin in Patients With Nonvalvular AF Undergoing PCI) trial, were more likely to be older and have higher $\mathrm{CHA}_{2} \mathrm{DS}_{2}-\mathrm{VAS}_{\mathrm{C}}$ and HAS-BLED scores. ${ }^{17}$ Although limited by smaller sample size and an imbalance of warfarin (61\% of prior OAC) and NOAC (39\% of prior $\mathrm{OAC})$ use, there was no interaction between all prior OAC usage and the trial's primary endpoint (ISTH major or CRNM bleeding). Although the authors appropriately acknowledged the small sample size and caution associated with interpretation, in RE-DUAL PCI the prior NOAC group had no reduction in the primary endpoint between dabigatran dual therapy and warfarin triple therapy. Specifically, in those with prior NOAC, the primary endpoint was $7.9 \%$ with dabigatran $110 \mathrm{mg}$ dual 


\begin{tabular}{|c|c|c|c|}
\hline Event & \multicolumn{2}{|c|}{$\begin{array}{l}\text { KM\% at } 6 \text { months } \\
\text { Apixaban VKA }\end{array}$} & $\begin{array}{c}\text { Hazard Ratio } \\
\text { Apixaban vs. VKA }\end{array}$ \\
\hline \multicolumn{4}{|c|}{ ISTH Major/CRNM Bleeding } \\
\hline No Prior OAC & 10.9 & 15.6 & $0.67(0.53-0.85)$ \\
\hline Prior NOAC & 10.1 & 15.6 & $0.63(0.45-0.87)$ \\
\hline Prior VKA & 12.6 & 15.3 & $0.80(0.57-1.12)$ \\
\hline \multicolumn{4}{|c|}{ ISTH Major Bleeding } \\
\hline No Prior OAC & 3.0 & 5.2 & $0.57(0.37-0.89)$ \\
\hline Prior NOAC & 3.1 & 4.2 & $0.70(0.38-1.30)$ \\
\hline Prior VKA & 3.7 & 5.3 & $0.68(0.38-1.23)$ \\
\hline \multicolumn{4}{|c|}{ All Cause Death or Rehospitalizatiol } \\
\hline No Prior OAC & 22.9 & 27.8 & $0.80(0.67-0.94)$ \\
\hline Prior NOAC & 25.0 & 30.3 & $0.79(0.64-0.98)$ \\
\hline Prior VKA & 24.7 & 24.4 & $0.99(0.77-1.27)$ \\
\hline \multicolumn{4}{|c|}{ All Cause Death or Ischemic Event } \\
\hline No Prior OAC & 7.9 & 7.3 & $1.04(0.77-1.40)$ \\
\hline Prior NOAC & 4.7 & 6.4 & $0.75(0.46-1.21)$ \\
\hline Prior VKA & 5.1 & 5.3 & $1.02(0.60-1.74)$ \\
\hline \multicolumn{4}{|c|}{ Myocardial Infarction } \\
\hline No Prior OAC & 4.7 & 3.4 & $1.30(0.85-1.97)$ \\
\hline Prior NOAC & 1.5 & 3.9 & $0.36(0.17-0.77)$ \\
\hline Prior VKA & 2.5 & 3.3 & $0.82(0.40-1.67)$ \\
\hline
\end{tabular}
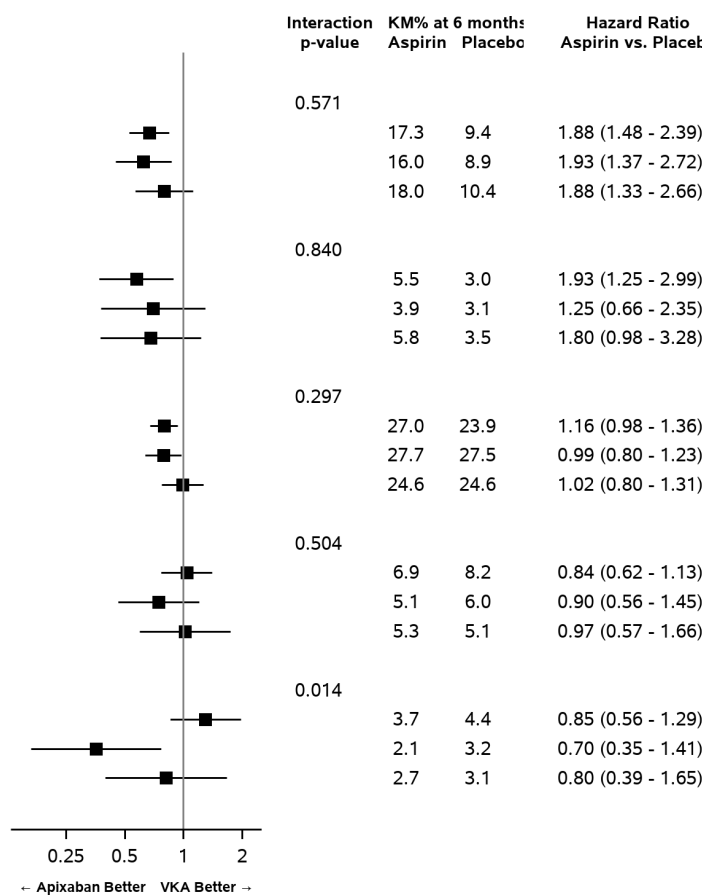

-value

0.993

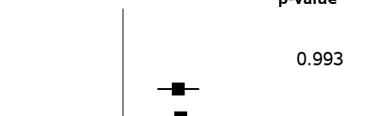

.531

469

0.888

Figure 1 Kaplan-Meier event rates, HRs with assessment for interaction between no prior OAC, prior NOAC and prior VKA for apixaban compared with VKA and aspirin compared with aspirin placebo. ISTH, vitamin K antagonists; KM, Kaplan-Meier; NOAC, non-vitamin $\mathrm{K}$ antagonist OAC; OAC, oral anticoagulant; VKA, vitamin $\mathrm{K}$ antagonists.

therapy compared with $5.6 \%$ with warfarin triple therapy (HR $1.37,95 \%$ CI -0.55 to 3.41 ) and $2.6 \%$ with dabigatran $150 \mathrm{mg}$ dual therapy compared with $4.7 \%$ with warfarin triple therapy (HR 0.55 , 95\% CI 0.11 to 2.83 ). In the AUGUSTUS trial, the lower rate of the primary endpoint (ISTH major or CRNM bleeding) with apixaban compared with VKA was consistent in those with or without prior OAC use and in the 3-way comparison between prior NOAC, prior VKA and no prior OAC.

\section{Limitations}

The AUGUSTUS study was not powered nor designed to assess the impact of prior OAC use in patients at the time of randomisation. Further, AUGUSTUS enrolled patients with ACS with or without PCI, a unique feature of this study but the differences in baseline characteristics (eg, greater proportion of those with elective PCI in the prior OAC subgroup), together with unmeasured confounders, could contribute to the observed associated outcome differences, despite robust attempts at multivariable adjustment. Accordingly, interpretation of the findings beyond the primary endpoint should be undertaken with caution.

\section{CONCLUSION}

Although patients enrolled in AUGUSTUS with prior OAC use, compared with those without prior OAC use, had increased comorbidities with associated higher $\mathrm{CHA}_{2} \mathrm{DS}_{2}$-VASc and HAS-BLED scores, they had no increased risk of bleeding complications and lower risk of ischaemic complications. In patients with AF and ACS and/or elective PCI, clinicians can be assured that the results of the AUGUSTUS trial can be applied to patients regardless of their prior OAC status.

\section{Author affiliations}

${ }^{1}$ Cardiac Sciences, University of Alberta and Mazankowski Alberta Heart Institute, Edmonton, Alberta, Canada

${ }^{2}$ Medicine, Regina Qu'Appelle Health Region, Regina, Saskatchewan, Canada ${ }^{3}$ Cardiology, Duke Clinical Research Institute and Duke University School of Medicine, Durham, North Carolina, USA

${ }^{4}$ Bristol-Myers Squibb Co, Princeton, New Jersey, USA

${ }^{5}$ Cardiology, Duke University School of Medicine, Durham, North Carolina, USA

${ }^{6}$ Department of Cardiology, Swiss Cardiovascular Center, Bern, Switzerland

${ }^{7}$ Cardiology, Pinnacle Heart and Vascular Institue, Harrisburg, Pennsylvania, USA

${ }^{8}$ Cardiology, Carol Davila University of Medicine and Pharmacy, Bucuresti, Romania

${ }^{9}$ Cardiology, Oslo University Hospital and University of Oslo, Oslo, Norway

${ }^{10}$ Cardiology, National Scientific Center Academician M D Strazhesko Institute of Cardiology of the National Academy of Medical Sciences of Ukraine, Kiiv, Ukraine

${ }^{11}$ Cardiology, Icahn School of Medicine at Mount Sinai, New York, New York, USA

${ }^{12}$ Canadian Heart Research Centre, Toronto, Ontario, Canada

${ }^{13}$ Terrence Donnelly Heart Centre, St Michael's Hospital, Toronto, Ontario, Canada

Acknowledgements We thank Elizabeth E.S. Cook, of the Duke Clinical Research Institute, for providing editorial assistance.

Contributors RW, RL, JHA and SG identified the subgroup analysis of interest and designed the initial proposal. DMW conducted the statistical analysis. RW wrote the first draft of the manuscript and all authors provided critical review and revision. $\mathrm{RW}$ is responsible for the overall content as guarantor.

Funding The AUGUSTUS trial was funded by Bristol Myers Squibb, Princeton, NJ and Pfizer, New York, New York, USA.

Competing interests RW: Research grant support (eg, steering committee or data and safety monitoring committee) and/or speaker/consulting honoraria (eg, advisory boards) from: AstraZeneca, Bayer, Boehringer Ingelheim, Bristol Myers Squibb/Pfizer, HLS Therapeutics, and Pfizer. PD: reports no conflicts of interest. RL: Institutional research grants and consulting fees from Bristol Myers Squibb, Pfizer, GlaxoSmithKline, Medtronic PLC, and Sanofi; and consulting fees from Amgen, Bayer, and Boehringer Ingelheim. Wojdyla: Nothing to report. RA: 
Employee of Bristol Myers Squibb. CBG: Research grants from Bayer, Boehringer Ingelheim, Bristol Myers Squibb, Daiichi Sankyo, Janssen, Pfizer, Armetheon, AstraZeneca, US Food \& Drug Administration, GlaxoSmithKline, The Medicines Company, Medtronic Foundation, Medtronic, and Novartis; consulting fees from Bayer, Boehringer Ingelheim, Boston Scientific, Bristol Myers Squibb, Daiichi Sankyo, Janssen, Pfizer, Abbvie, Armetheon, Astra Zeneca, Eli Lilly, Gilead, GlaxoSmithKline, Hoffmann-La Roche, The Medicines Company, National Institutes of Health, Novartis, Sirtex, Verseon, Apple, Medscape, Merck, Novo Nordisk, Roche Diagnostics, and Rho Pharmaceuticals. SW: Research and educational grants to the institution from Abbott, Amgen, BMS, Bayer, Boston Scientific, Biotronik, Cardinal Health, CardioValve, CSL Behring, Daiichi Sankyo, Edwards Lifesciences, Johnson\&Johnson, Medtronic, Querbet, Polares, Sanofi, Terumo, Sinomed. SW serves as unpaid advisory board member and/or unpaid member of the steering/ executive group of trials funded by Abbott, Abiomed, Amgen, Astra Zeneca, BMS, Boston Scientific, Biotronik, Cardiovalve, Edwards Lifesciences, MedAlliance, Medtronic, Novartis, Polares, Sinomed, V-Wave and Xeltis, but has not received personal payments by pharmaceutical companies or device manufacturers. He is also member of the steering/executive committee group of several investigatedinitiated trials that receive funding by industry without impact on his personal remuneration. SW is an unpaid member of the Pfizer Research Award selection committee in Switzerland. ANV: Consulting for Medtronic. DV: Research grants from BMS/Pfizer, Boehringer Ingelheim, Bayer, and Daiichi Sankyo; personal fees from Boehringer Ingelheim, Bayer, and Daiichi Sankyo. Halvorsen: Speaker fees from Bayer, Amgen, AstraZeneca, Boehringer Ingelheim, Bristol Myers Squibb, Pfizer, Sanofi, and Merck. AP: Research grants and consulting/speaker fees from Bayer, AstraZeneca, Sanofi-Aventis, NovoNordisk; research grants from Pfizer, Bristol Myers Squibb, Amgen, CSL Behring. Bahit: Lecture fees from Bristol Myers Squibb, Pfizer; consulting fees from Merck Sharp \& Dohme, and CSL Behring. RM: Institutional research grants from AstraZeneca, Bayer, Beth Israel Deaconess, Bristol Myers Squibb/Sanofi, CSL Behring, Eli Lilly/Daiichi Sankyo, Medtronic, Novartis, and OrbusNeich; consulting fees from Boston Scientific, Abbott Vascular, Medscape, Siemens Medical Solutions, Roivant Sciences, and Sanofi; consulting (no fees) from Regeneron Pharmaceuticals; institutional consulting fees from Abbott Vascular, Spectranetics/Phillips/Volcano Corporation, Bristol Myers Squibb, Novartis, and Watermark Research; executive committee member for Janssen Pharmaceuticals and Bristol Myers Squibb; has $<1 \%$ equity in Claret Medical and Elixir Medical. AP: Institutional research grants and consulting fees/honoraria from Bristol Myers Squibb and CSL Behring; institutional research grants from AstraZeneca, CryoLife, US Food and Drug Administration, National Institutes of Health, Sanofi, VoluMetrix, and Boehringer Ingelheim; and consulting fees/honoraria from Pfizer, AbbVie Pharmaceuticals, NovoNordisk, Portola Pharmaceuticals, Quantum Genetics, Teikoku Pharmaceuticals, VA Cooperative Studies Program, and Zafgen. SG: Research grant support (eg, steering committee or data and safety monitoring committee) and/or speaker/consulting honoraria (eg, advisory boards) from: Amgen, AstraZeneca, Bayer, Boehringer Ingelheim, Bristol Myers Squibb, CSL Behring, Daiichi-Sankyo/American Regent, Eli Lilly, Esperion, Ferring Pharmaceuticals, GlaxoSmithKline, HLS Therapeutics, Janssen/Johnson \& Johnson, Merck, Novartis, Novo Nordisk A/C, Pendopharm, Pfizer, Regeneron, Sanofi, Servier; and salary support/honoraria from the Heart and Stroke Foundation of Ontario/ University of Toronto (Polo) Chair, Canadian Heart Research Centre and MD Primer, Canadian VIGOUR Centre, Duke Clinical Research Institute, New York University Clinical Coordinating Centre and PERFUSE Research Institute.

\section{Patient consent for publication Not applicable.}

Ethics approval The trial was conducted in compliance with the Declaration of Helsinki and Good Clinical Practice, as defined by the International Conference on Harmonisation. The study protocol was approved by ethics committees or institutional review boards at participating sites.

\section{Provenance and peer review Not commissioned; externally peer reviewed.}

Data availability statement Data are available on reasonable request. Duke Clinical Research Institute manages the AUGUSTUS trial data base.

Open access This is an open access article distributed in accordance with the Creative Commons Attribution Non Commercial (CC BY-NC 4.0) license, which permits others to distribute, remix, adapt, build upon this work non-commercially, and license their derivative works on different terms, provided the original work is properly cited, appropriate credit is given, any changes made indicated, and the use is non-commercial. See: http://creativecommons.org/licenses/by-nc/4.0/.
ORCID iD

Robert C. Welsh http://orcid.org/0000-0003-2613-9142

\section{REFERENCES}

1 Depta JP, Bhatt DL. Atherothrombosis and atrial fibrillation: important and often overlapping clinical syndromes. Thromb Haemost 2010;104:657-63.

2 Goto S, Bhatt DL, Röther J, et al. Prevalence, clinical profile, and cardiovascular outcomes of atrial fibrillation patients with atherothrombosis. Am Heart J 2008;156:855-63.

3 Ruff CT, Bhatt DL, Steg PG, et al. Long-term cardiovascular outcomes in patients with atrial fibrillation and atherothrombosis in the REACH registry. Int J Cardiol 2014;170:413-8.

4 Cannon CP, Bhatt DL, Oldgren J, et al. Dual antithrombotic therapy with dabigatran after $\mathrm{PCl}$ in atrial fibrillation. $N$ Engl $\mathrm{J}$ Med 2017;377:1513-24.

5 Gibson CM, Mehran R, Bode C, et al. Prevention of bleeding in patients with atrial fibrillation undergoing $\mathrm{PCl}$. $N$ Engl J Med 2016;375:2423-34.

6 Lopes RD, Heizer G, Aronson R, et al. Antithrombotic therapy after acute coronary syndrome or $\mathrm{PCl}$ in atrial fibrillation. $\mathrm{N} \mathrm{Engl} \mathrm{J} \mathrm{Med}$ 2019;380:1509-24

7 Vranckx P, Valgimigli M, Eckardt L, et al. Edoxaban-based versus vitamin $\mathrm{K}$ antagonist-based antithrombotic regimen after successful coronary stenting in patients with atrial fibrillation (ENTRUSTAF PCI): a randomised, open-label, phase $3 \mathrm{~b}$ trial. Lancet 2019;394:1335-43.

8 Gargiulo G, Goette A, Tijssen J, et al. Safety and efficacy outcomes of double vs. triple antithrombotic therapy in patients with atrial fibrillation following percutaneous coronary intervention: a systematic review and meta-analysis of non-vitamin $\mathrm{K}$ antagonist oral anticoagulant-based randomized clinical trials. Eur Heart $J$ 2019;40:3757-67.

9 Dewilde WJM, Janssen PW, Kelder JC, et al. Uninterrupted oral anticoagulation versus bridging in patients with long-term oral anticoagulation during percutaneous coronary intervention: subgroup analysis from the WOEST trial. Eurolntervention 2015;11:381-90.

10 Granger CB, Lopes RD, Hanna M, et al. Clinical events after transitioning from apixaban versus warfarin to warfarin at the end of the apixaban for reduction in stroke and other thromboembolic events in atrial fibrillation (ARISTOTLE) trial. Am Heart $J$ 2015;169:25-30.

11 Lahtela H, Rubboli A, Schlitt A, et al. Heparin bridging vs. uninterrupted oral anticoagulation in patients with atrial fibrillation undergoing coronary artery stenting. results from the AFCAS registry. Circ J 2012;76:1363-8.

12 Mahaffey KW, Hellkamp AS, Patel MR, et al. End of study transition from study drug to open-label vitamin $\mathrm{K}$ antagonist therapy: the ROCKET AF experience. Circ Cardiovasc Qual Outcomes 2013;6:470-8.

13 Ruff CT, Giugliano RP, Braunwald E, et al. Transition of patients from blinded study drug to open-label anticoagulation: the ENGAGE AFTIMI 48 trial. J Am Coll Cardiol 2014;64:576-84.

14 Lopes RD, Vora AN, Liaw D, et al. An open-label, $2 \times 2$ factorial, randomized controlled trial to evaluate the safety of apixaban vs. vitamin $\mathrm{K}$ antagonist and aspirin vs. placebo in patients with atrial fibrillation and acute coronary syndrome and/or percutaneous coronary intervention: rationale and design of the AUGUSTUS trial. Am Heart J 2018;200:17-23.

15 Bouillon K, Bertrand M, Maura G, et al. Risk of bleeding and arterial thromboembolism in patients with non-valvular atrial fibrillation either maintained on a vitamin $\mathrm{K}$ antagonist or switched to a non-vitamin $\mathrm{K}$-antagonist oral anticoagulant: a retrospective, matched-cohort study. Lancet Haematol 2015;2:e150-9.

16 Mahaffey KW, Wojdyla D, Hankey GJ, et al. Clinical outcomes with rivaroxaban in patients transitioned from vitamin $\mathrm{K}$ antagonist therapy: a subgroup analysis of a randomized trial. Ann Intern Med 2013;158:861-8.

17 Maura G, Blotière P-O, Bouillon K, et al. Comparison of the short-term risk of bleeding and arterial thromboembolic events in nonvalvular atrial fibrillation patients newly treated with dabigatran or rivaroxaban versus vitamin $\mathrm{K}$ antagonists: a French nationwide propensity-matched cohort study. Circulation 2015;132:1252-60. 